\title{
Decompensated Heart Failure with Mid-Range Ejection Fraction: Epidemiology and In-Hospital Mortality Risk Factors
}

\author{
Gabriela Paiva Cavalcanti, ${ }^{\circledR}$ Camila Sarteschi, ${ }^{\circledR}$ Glory Eithne Sarinho Gomes, ${ }^{\circledR}$ Carolina de Araújo Medeiros, ${ }^{(0}$ \\ José Henrique Martins Pimentel, ${ }^{\circledR}$ André Rabelo Lafayette, ${ }^{\circledR}$ Maria Celita Almeida, ${ }^{\circledR}$ Paulo Sérgio Rodrigues \\ Oliveira, ${ }^{\circledR}$ Silvia Marinho Martins ${ }^{(}$
}

Real Hospital Português de Beneficência em Pernambuco, Recife, PE - Brazil

\section{Abstract}

Background: Recently, a new HF entity, with LVEF between 40-49\%, was presented to comprehend and seek better therapy for HF with preserved LVEF (HFpEF) and borderline, in the means that HF with reduced LVEF (HFrEF) already has well-defined therapy in the literature.

Objective: To compare the clinical-therapeutic profile of patients with HF with mid-range LVEF (HFmrEF) with HFpEF and HFrEF and to verify predictors of hospital mortality.

Method: Historical cohort of patients admitted with decompensated HF at a supplementary hospital in Recife/ PE between April/2007 - August/2017, stratified by LVEF ( $<40 \% / 40-49 / \geq 50 \%$ ), based on the guideline of the European Society of Cardiology (ESC) 2016. The groups were compared and Logistic Regression was used to identify predictors of independent risk for in-hospital death.

Results: A sample of 493 patients, most with HFrEF (43\%), HFpEF (30\%) and HFmrEF (26\%). Average age of 73 ( \pm 14 ) years, $59 \%$ men. Hospital mortality $14 \%$, readmission within 30 days $19 \%$. In therapeutics, it presented statistical significance among the 3 groups, spironolactone, in HFrEF patients. Hospital death and readmission within 30 days did not make difference. In the HFmrEF group, factors independently associated with death were: valve disease (OR: 4.17, CI: 1.01-9.13), altered urea at admission (OR: 6.18, CI: 1.78-11.45) and beta-blocker hospitalization (OR: 0.29, CI: 0.08-0.97). In HFrEF, predictors were: prior renal disease (OR: 2.84, CI: 1.19-6.79), betablocker at admission (OR: 0.29, CI: 0.12-0.72) and ACEI/ ARB (OR: 0.21, CI: 0.09-0.49). In HFpEF, only valve disease (OR: 4.61, CI: 1.33-15.96) and kidney disease (OR: 5.18, CI: 1.68-11.98) were relevant.

Conclusion: In general, HFmrEF presented intermediate characteristics between HFrEF and HFpEF. Independent predictors of mortality may support risk stratification and management of this group. (Int J Cardiovasc Sci. 2020;33(1):45-54)

Keywords: Heart Failure/physiopatology; Stroke Volume/physiology; Prognosis; Hospital Mortality; Epidemiology.

\section{Introduction}

Heart failure (HF) is a clinical syndrome with high global prevalence, responsible for elevated mortality and readmission rates. ${ }^{1}$ It is often categorized according to left ventricular ejection fraction (LVEF), historically defined as heart failure with reduced ejection fraction
(HFrEF) and heart failure with preserved ejection fraction (HFpEF). Unlike HFrEF, whose therapy in terms of mortality reduction has been well-defined, HFpEF remains a syndrome that still poses diagnostic challenges, with no well-established treatment. ${ }^{2}$ Most HFrEF clinical trials have included patients with $\mathrm{EF}<35-40 \%$, whereas HFpEF trials used $\mathrm{EF}>50 \%$, EF $>45 \%$ or $\mathrm{EF}>40 \%$ as 
inclusion criteria. Other HF studies reported, within large populations, a broad proportion of patients with midrange LVEF, between $40-50 \%$ still poorly characterized..$^{1-4}$

In 2013, the American Heart Association (AHA) ${ }^{5}$ proposed in its guidelines the inclusion of a new group, HF with borderline EF (EF: 41-49\%). Recently, the European Society of Cardiology guidelines has emphasized this new classification, recognizing a new entity of HF with mid-range ejection fraction (HFmrEF), defined as the presence of signs and symptoms of heart failure, EF: $40-49 \%$, elevated natriuretic peptides levels and at least 1 additional criterion: structural heart disease and/or diastolic dysfunction. ${ }^{6}$ Until now, there is no consensus on the most appropriate LVEF cut-off to differentiate the HF groups or the prognosis and the real benefits of the treatment in this particular group of HF with mid-range ejection fraction. In view of such a scenario, the objective of this study was to identify and compare the clinical and therapeutic profile of HF patients, stratifying them by LVEF, according with the 2016 European Society of Cardiology (ESC) guidelines, and to identify specific independent predictors of inhospital mortality in each group.

\section{Methods}

Retrospective hospital-based cohort of patients admitted to a reference hospital of the Supplemental Healthcare System, in Recife/PE, between April 2007 and August 2017.

The sample included patients admitted with a diagnosis of decompensated heart failure, aged over 18 years, who had been hospitalized for at least 24 hours, in functional classes III and IV, according to the New York Heart Association (NYHA) functional classification ${ }^{7}$ and who had undergone echocardiography at the service or had recent echocardiographic data available (obtained within less than 3 months), including a description of the LVEF.

Based on the guideline of the European Society of Cardiology (ESC) $2016^{6}$ and on the Brazilian guidelines published in 2018, ${ }^{8}$ patients were divided into 3 distinct groups of $\mathrm{HF}$, according to LVEF on echocardiogram: HFrEF (EF<40\%), HFmrEF (EF: $40-49 \%$ ) and HFpEF $(\geq 50 \%)$.

LVEF was calculated by echocardiography, using the Teichholz' M-mode volume method, or the modified Simpson's formula for measurement of LV end-systolic and end-diastolic diameter, in the 4-chamber apical plane, in accordance with current guidelines, all performed in the echocardiography sector of the hospital. ${ }^{9}$

Data collection included hospital admission data, inhospital mortality data and readmission within 30 days. The information were obtained from the consultation of medical records and complemented, whenever necessary, by contact with the assisting physician. A structured questionnaire was chosen as data collection instrument, including demographic and clinical variables, clinical exam at admission, complementary exams and the treatment adopted. The outcome of interest was inhospital mortality.

The etiology of HF and the cause of decompensation were defined by the assistant physician on medical report. Ischemic, hypertensive, valvular, idiopathic, and other etiologies (lower proportion group or with no confirmed diagnosis by the assistant physician) were investigated.

Some continuous variables were changed into categories for analytical purposes; ${ }^{10}$ age $\left(<65\right.$ and ${ }^{3} 65$ years), systolic blood pressure (SBP $<115 \mathrm{mmHg}$ and ${ }^{3}$ $115 \mathrm{mmHg})$, heart rate $(£ 80 \mathrm{bpm}$ and $>80 \mathrm{bpm})$, serum creatinine (altered: $>1,3 \mathrm{mg} / \mathrm{dl}$ men and $>1,1 \mathrm{mg} / \mathrm{dl}$ women), plasma sodium (altered: $<130 \mathrm{mEq} / \mathrm{l}$ ) and urea (altered: ${ }^{3} 92 \mathrm{mg} / \mathrm{dl}$ ). The presence of anemia was defined, according to the WHO criteria $(\mathrm{Hb}<13.0 \mathrm{~g} / \mathrm{dL}$ in men and $\mathrm{Hb}<12.0 \mathrm{~g} / \mathrm{dL}$ in women). ${ }^{11}$

\section{Statistical Analysis}

Demographic and clinical characteristics of patients were analyzed using descriptive statistics: mean and standard deviation (SD) for quantitative variables and absolute and relative frequencies for qualitative variables. Data normality was verified using the KolmogorovSmirnov test. To compare the LVEF groups, in relation to the qualitative variables, the Qui-square test was utilized, and, for quantitative variables, analysis of variance methodology was used for normal distribution, Kruskal-Wallis test for not normal. Bivariate analysis, using Pearson's Chi-square, was carried out as a strategy to assess the relation between the outcome (in-hospital death) and the independent variables, studied for each group individually. All variables related to in-hospital death with a $p$ value $<0.20$ in the bivariate analysis were considered for inclusion in multiple logistic regression model. The stepwise forward method was used to select the final model. Once the final model was chosen, calibration was assessed using Hosmer Lemeshow $>\mathrm{S}$ goodness of fit test. The IBMSPSS Statistics for Windows 
(Version 21.0. Armonk, NY: IBM. Corp.) software was used to perform statistical analysis. The level of significance assumed was $5 \%$.

The research project was approved by the Ethics Committee in Research of the Catholic University of Pernambuco UNICAP/PE (CAAE: 70897517.8.0000.5206). The study was conducted in accordance with the principles of the Declaration of Helsinki.

\section{Results}

A sample of 599 patients was collected between January 2007 and March 2017. Out of these, 106 did not have any LVEF data available and were not included in the analysis. A total of 493 patients fulfilled the inclusion and exclusion criteria of the study.

From the sample studied, most HF individuals (43\%) were classified with LVEF $<40 \%$, followed by $30 \%$ of with LVEF $\geq 50 \%$ and $26 \%$ with LVEF $40-49 \%$. The age of the patients varied from 20 to 99 years, with a mean of $73(\mathrm{SD}=14)$ years, $370(75 \%)$ were 65 years old or more, with men accounting for the majority of them (59\%), Functional Class (FC) IV (52\%), ischemic etiology (52\%), followed by hypertensive (19\%) and idiopathic (9\%) etiologies. The outcome in-hospital death was $14 \%$ of the sample. Nineteen percent of patients were readmitted within 30 days.

Among the most frequent comorbidities found, we can highlight: systemic arterial hypertension (SAH) in $87 \%$ of patients; diabetes mellitus (DM) in 51\% and coronary insufficiency $(\mathrm{CI})$ in $59 \%$. In a comparative analysis, the groups were significantly distinct with regard to $\mathrm{SAH}$ and $\mathrm{CI}$, being more frequent in HFmrEF patients; valve disease and alcoholism were more common in HFpEF and $\mathrm{HFrEF}$, respectively. The main cause for decompensation was acute coronary syndrome - ACS (38\%), followed by infection (33\%) and arrhythmia (atrial fibrillation). In relation to pharmacological therapeutics during hospitalization, the use of beta-blockers was observed in $73 \%$ of patients, angiotensin converting enzyme inhibitors (ACEi) / angiotensin II receptor blockers (ARB) in $68 \%$ and aldosterone receptor antagonist spironolactone in $42 \%$.

When the three groups were comparatively analyzed (Table 1), HFpEF and HFmrEF patients were older, with a prevalence of female patients, compared to the HFrEF group, which had a prevalence of males (68\%). Ischemic and idiopathic etiologies were observed in a higher percentage of HFrEF and HFmrEF patients, whereas the hypertensive and valve etiologies were more frequent among those with HFpEF. ACS was the main cause for decompensation, being more frequent in $\mathrm{HFmrEF}(46 \%)$, followed by $\mathrm{HFrEF}(39 \%)$. Hypertension and $\mathrm{CI}$ were more prevalent among HFmrEF patients ( $93 \%$ and $67 \%$, respectively), whereas valve disease accounted for a higher proportion in $\mathrm{HFpEF}$, and alcoholism in the HFrEF and HFmrEF groups.

In relation to systolic blood pressure (SBP) at admission, the values were lower in patients with HFrEF. As to heart rate (HR) and NYHA functional

Table 1 - Comparison of groups in relation to demographic, clinical, therapeutic, laboratory and outcome variables

\begin{tabular}{|c|c|c|c|c|c|}
\hline \multirow{2}{*}{ Variables } & \multirow{2}{*}{ Total } & \multicolumn{3}{|c|}{ LVEF } & \multirow{2}{*}{$\mathbf{p}$} \\
\hline & & $<40 \%$ & $40-49 \%$ & $\geq \mathbf{5 0} \%$ & \\
\hline Age - Mean (SD) & $42.9(13.6)$ & $70.3(14.4)^{+/++}$ & $75.2(12.4)$ & $74.6(12,9)$ & 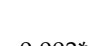 \\
\hline Age $\geq 65$ years (\%) & 75.2 & 67.6 & 80.6 & 81.3 & \\
\hline Male (\%) & 58.6 & 67.8 & 58.9 & 45.3 & $<0.001^{*}$ \\
\hline FC IV (\%) & 52.3 & 55.3 & 52.4 & 47.9 & 0.392 \\
\hline Etiology (\%) & & & & & $<0001^{*}$ \\
\hline Ischemic & 52.3 & 57.1 & 56.3 & 41.8 & \\
\hline Hipertensive & 19.5 & 11.3 & 18.0 & 32.9 & \\
\hline Idiopathic & 8.6 & 10.4 & 11.7 & 3.4 & \\
\hline Valve & 11.5 & 8.0 & 10.2 & 17.8 & \\
\hline Others & 8.0 & 13.2 & 3.9 & 4.1 & \\
\hline
\end{tabular}




\section{Cont. Table 1 - Comparison of groups in relation to demographic, clinical, therapeutic, laboratory and outcome variables}

\begin{tabular}{|c|c|c|c|c|c|}
\hline \multirow{2}{*}{ Variables } & \multirow{2}{*}{ Total } & \multicolumn{3}{|c|}{ LVEF } & \multirow{2}{*}{$\mathbf{p}$} \\
\hline & & $<40 \%$ & $40-49 \%$ & $\geq \mathbf{5 0} \%$ & \\
\hline ACS-HF (\%) & 38.0 & 38.8 & 45.7 & 30.2 & $0.028^{*}$ \\
\hline \multicolumn{6}{|l|}{ Comorbidities } \\
\hline DM & 50.7 & 44.9 & 58.1 & 52.7 & 0.050 \\
\hline SAH & 87.2 & 82.7 & 93.8 & 88.0 & $0.011^{*}$ \\
\hline IC & 58.6 & 60.7 & 67.4 & 48.0 & $0.003^{*}$ \\
\hline Valve disease & 10.3 & 6.1 & 10.1 & 16.7 & $0.005^{*}$ \\
\hline Kidney disease & 34.5 & 36.0 & 34.9 & 32.0 & 0.729 \\
\hline COPD/Asma & 19.5 & 21.0 & 17.1 & 19.3 & 0.666 \\
\hline Neoplasia & 8.1 & 5.1 & 10.9 & 10.0 & 0.103 \\
\hline Alcoholism & 18.3 & 22.4 & 20.2 & 10.7 & $0.014^{*}$ \\
\hline Smoking & 20.1 & 22.4 & 20.2 & 16.7 & 0.401 \\
\hline SBP (mmHg) - Mean (SD) & $136.3(31.8)$ & $128.5(27.9)^{+/++}$ & $139.2(31.9)$ & $145.0(34.4)$ & $<0.001^{*}$ \\
\hline HR (bpm) - Mean (SD) & $87,4(20.8)$ & $87.9(21.6)$ & $88,4(20.6)$ & $85.9(19.6)$ & 0.557 \\
\hline $\mathrm{AF}(\%)$ & 22.8 & 20.5 & 19.7 & 28.8 & 0.144 \\
\hline EDD - Median (P25 - P75) & $58(50-65)$ & $65(58-70)^{+/++}$ & $55(52-62)^{+++}$ & $47(45-85)$ & $<0.001^{*}$ \\
\hline SPAP - Median (P25 - P75) & $46(39-57)$ & $45(40-56)$ & $42(37-56)$ & $48(42-59)$ & 0.870 \\
\hline Moderate/severe MR (\%) & 47.9 & 55.2 & 56.1 & 30.3 & $<0.001^{*}$ \\
\hline Moderate/severe TR (\%) & 22.6 & 25.9 & 23.8 & 16.7 & 0.128 \\
\hline Increased RV (\%) & 19.6 & 30.2 & 12.9 & 11.0 & $<0.001^{*}$ \\
\hline LVEF - Mean (SD) & $43.2(14.3)$ & $30.2(6.6)$ & $44.4(2.7)$ & $60.7(7,3)$ & - \\
\hline Sodium Ad - Mean (SD) & $137.2(5.8)$ & $137.6(5.5)$ & $137.1(5.9)$ & $136.7(6.2)$ & 0.387 \\
\hline Urea Ad - Mean (SD) & $64.9(39.6)$ & $68.5(42.9)$ & $64.7(40.7)$ & $60.1(32.6)$ & 0.141 \\
\hline Creatinine Ad - Mean (DP) & $1.5(0.9)$ & $1.4(0.8)$ & $1.4(0.9)$ & $1.5(1.1)$ & 0.681 \\
\hline $\mathrm{Hb}$ Ad - Mean (SD) & $12.2(2.3)$ & $12.6(2.3)^{+/++}$ & $11.9(1.9)$ & $11.8(2.2)$ & $0.002^{*}$ \\
\hline BNP Ad Median $\left(\mathrm{P}_{25}-\mathrm{P}_{75}\right)$ & $\begin{array}{c}6,000 \\
(2,769-15,927)\end{array}$ & $\begin{array}{c}7,249 \\
(3,473-19,610)^{+/++}\end{array}$ & $\begin{array}{c}8,421 \\
(5,304-22,352)^{+++}\end{array}$ & $\begin{array}{c}2,827 \\
(1,685-6,285)\end{array}$ & $0.015^{*}$ \\
\hline B-blocker (\%) & 73.3 & 77.8 & 72.9 & 67.1 & 0.076 \\
\hline ACEi /ARB (\%) & 66.5 & 69.2 & 64.3 & 68.7 & 0.626 \\
\hline Digoxin (\%) & 22.0 & 28.6 & 17.2 & 16.8 & $0.008^{*}$ \\
\hline SPIR (\%) & 41.7 & 52.8 & 38.8 & 28.2 & $<0.001^{*}$ \\
\hline In-hospital death (\%) & 14.0 & 18.2 & 12.4 & 12.0 & 0.173 \\
\hline Readmission within $30 \mathrm{~d}(\%)$ & 19.2 & 19.9 & 22.1 & 15.7 & 0.498 \\
\hline
\end{tabular}


class VI, there were no statistical differences between the categories of HF.

With regard to the laboratory variables, the groups were distinct in terms of natriuretic peptides (NTProBNP) levels and anaemia, which were higher among patients with HFrEF and HFmrEF. LV end-diastolic diameter (LVEDD) values were higher among HFrEF patients compared to HFpEF patients. Moderate to severe mitral regurgitation (MR) was commonly observed in HFrEF and HFmrEF.

In-hospital pharmacological treatment of patients with DHF is presented in Chart 1. Beta-blockers, ACEi/ $\mathrm{ARB}$ and Spironolactone were used in 78\%, 69\% and $53 \%$ of HFrEF patients, respectively. However, statistical significance was only observed in the Spironolactone variable, which is more commonly used in patients with HFrEF. No statistical difference was observed between the groups in terms of in-hospital death and readmission within 30 days.

According to the bivariate analysis, the variables that presented a significant association with in-hospital death for patients with HFrEF were: advanced age, valve disease, kidney disease, peripheral vascular disease (PVD), urea, aneamia, beta-blocker and ACEi/ARB; for
HFmrEF: kidney disease, urea at admission, aneamia and beta-blocker; and for HFpEF: kidney disease, PVD and creatinine at admission.

The independent risk factors obtained by multivariate analysis for in-hospital death are shown in Table 2. In the worst outcomes, previous kidney disease was associated with HFrEF and HFpEF. Previous valve disease was related to HFmrEF and HFpEF, and increased urea levels, exclusively in HFmrEF. The use of medication, such as beta-blockers and ACEi/ARB, were associated with a better evolution in HFmrEF and $\mathrm{HFrEF}$, respectively.

It is worthy to highlight that HFrEF was associated with higher in-hospital mortality rates in patients with previous kidney disease (Odds Ratio (OR): 2.84, CI:1.196.79) and showed a 3.5 higher risk of in-hospital death for patients under no beta-blocker therapy and an almost 5 times higher risk for those under no treatment with ACE inhibitors or ARBs. HFmrEF was associated with higher in-hospital mortality rates for valve disease (OR: 4.17, CI: 1.01-9.13) and to altered levels of urea at admission (OR:6.18, CI:1.78-11.45), and the likelihood of death increased by 3.5 times in patients under no beta-blocker therapy. In relation to HFpEF patients, there was an

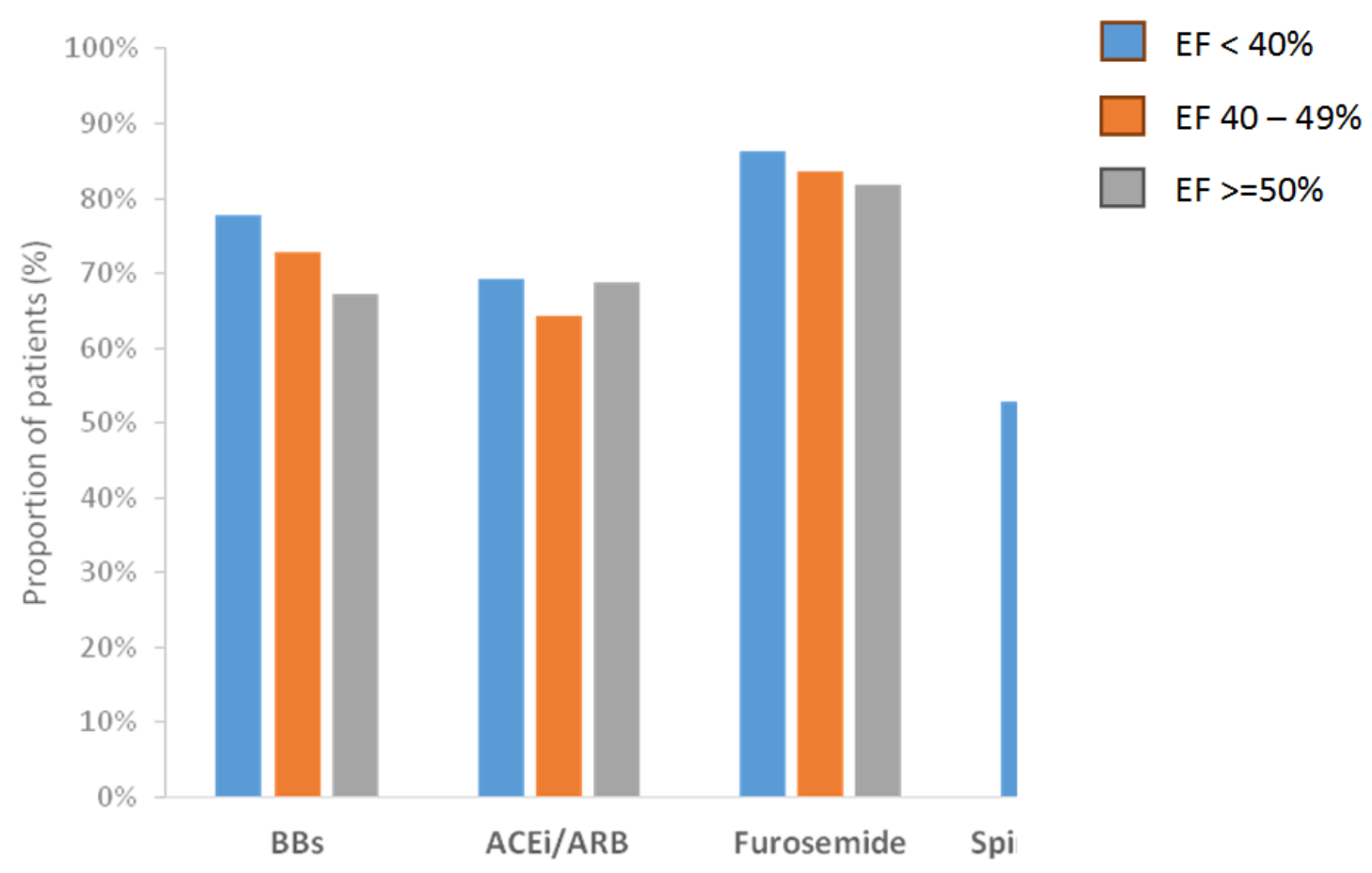

Chart 1 - Sample distribution, according to the drug administered during hospitalization. 
Table 2 - Results of Multivariate analysis for the in-hospital death outcome - p-value

\begin{tabular}{|c|c|c|c|c|c|c|}
\hline \multirow{2}{*}{ Variables } & $\mathrm{EF}<40 \%$ & \multirow{2}{*}{ P-value } & EF $40-49 \%$ & \multirow{2}{*}{ p-value } & $\mathrm{EF} \geq 50 \%$ & \multirow{2}{*}{ p-value } \\
\hline & OR (CI95\%) & & OR (CI95\%) & & OR (CI95\%) & \\
\hline Sex - Male & - & - & & 0.373 & - & - \\
\hline Age $\geq 65$ years & & 0.087 & - & - & & 0.182 \\
\hline FC IV & & 0.223 & & 0.090 & - & - \\
\hline Etiology & - & - & & 0.768 & - & - \\
\hline IC PR & - & - & & 0.494 & - & - \\
\hline Valve disease PR & & 0.084 & 4.17 (1.01-9.13) & 0.047 & $4.61(1.33-15.96)$ & 0.016 \\
\hline Kidney disease PR & $2.84(1.9-6.79)$ & 0.019 & & 0.192 & $5.18(1.68-11.98)$ & 0.004 \\
\hline COPD/Asma PR & & 0.724 & - & - & - & - \\
\hline PVD PR & & 0.120 & - & - & & 0.049 \\
\hline Sodium ALT & & 0.974 & & 0.199 & - & - \\
\hline Urea ALT & & 0.914 & $6.18(1.78-11.45)$ & 0.004 & & 0.911 \\
\hline Creatinine ALT & - & - & - & - & & 0.412 \\
\hline Aneamia & & 0.222 & & 0.274 & - & - \\
\hline BB INT. & $0.29(0.12-0.72)$ & 0.008 & $0.29(0.08-0.97)$ & 0.045 & - & - \\
\hline ACEi/ARB INT. & $0.21(0.09-0.49)$ & 0.001 & - & - & - & - \\
\hline SPIR. INT & & 0.260 & & 0.182 & - & - \\
\hline Furos. INT & & 0.068 & & 0.077 & - & - \\
\hline
\end{tabular}

association with valve disease (OR: 4.61, CI: 1.33-15.96) and kidney disease (OR: 5.18, CI: 1.68-11.98).

\section{Discussion}

\section{Clinical Profile}

The ICD ${ }^{12}$ classification is already well-defined, and its categorization according to LVEF measured by echocardiography is used to characterize the syndrome clinically and, particularly, to orientate the treatment. LVEF through echocardiography is considered easy to perform, of lower cost and can be applied at the bedside, when necessary. However, there are several limitations concerning its estimation, both technical (dependent observer, two-dimensional evaluation, intra- and inter-observer variability and inadequate acoustic window) and non-technical (mitral regurgitation, aortic stenosis, arrhythmias, myocarditis and Takotsubo syndrome), which may generate inaccurate measurements. ${ }^{13}$ Cardiac magnetic resonance imaging is considered the gold standard for assessing left ventricular (LV) systolic function, ${ }^{14}$ but it is not easily available in daily clinical practice. Although echocardiography does not seem to be the ideal method, it remains a practical and accessible tool for estimation of LVEF and the choice exam in all studies that have focused on HF treatment so far. ${ }^{15-17} \mathrm{It}$ is worthy to note that classifying HF patients is more complex than simply stratifying them by LVEF cut-off values because these patients have a high burden of cardiovascular and non-cardiovascular comorbidities, which may interact on different levels of LVEF, and may influence prognosis more than the LVEF category.

There was a discrete predominance of patients with HFrEF at this institution, in consonance with previous 
studies, which indicates that the profile of supplemental health care patients is pretty much similar to those from international registries ${ }^{10}$ and that it differs from Brazilian data when HFmrEF reaches the absolute majority..$^{18}$ The predominance in our study of older individuals with ischemic etiology is also compatible with data from developed countries. ${ }^{19-21}$ In-hospital death, which occurred in $14 \%$ of the population studied, is in accordance with data from the Brazilian registry of acute HF patients admitted to public and private hospitals. ${ }^{18}$

Twenty-six percent of the population presented HFmrEF, which corroborates the estimated range, from $10-20 \%$, in recent studies. ${ }^{22,23}$ These patients were aged over 65 years $(80 \%)$, with a higher proportion of females, similarly to the HFpEF profile. As for ischemic etiology, HFmrEF had a prevalence of $56 \%$ and was closer in value to the HFrEF group. Hypertensive etiology showed intermediate values in relation to the other two groups.

DHF associated with ACS was more prevalent among HFmrEF patients (46\%) compared to those from the other two groups. In Brazil, recent data have shown that the main cause of DHF is poor medication adherence, ${ }^{18}$ other studies presented different results. ${ }^{23}$ Data from OPTIMIZE-HF, ${ }^{24}$ a comprehensive European registry, were consistent with those reported in this study, which can be justified by differences between the profile and data of the population seen at supplemental health system and in the public health system.

HFmrEF presented with high comorbidity rates, such as diabetes mellitus, hypertension, IC and MI, and showed intermediate values for valve disease, kidney disease and alcoholism. It is also interesting to stress that left ventricular end-diastolic diameter values were intermediate, which indicates a possible transition stage between the other two HF groups. The similarities between HFmrEF and HFpEF suggest that HFmrEF may represent recovered or early stages of $\mathrm{HFrEF},{ }^{25,26}$ but other long-term echocardiographic follow-up studies in these patients are needed.

\section{Mortality and Prognostic Factors}

In-hospital mortality in HFmrEF was similar in absolute values to HFpEF but lower than HFrEF, although the study has no sufficient statistical power to prove this difference. The same pattern was observed in hospital readmission rates. The "benignity" of HFpEF has been documented in the literature. ${ }^{27}$ Data from the OPTIMIZE registry have shown lower in-hospital mortality rates in HFpEF patients. Nevertheless, the criterion adopted in this study was HFpEF (EF $\geq 40 \%$ ), and thus included those patients currently classified as HFmrEF, which poses limitations to comparisons. A meta-analysis involving over 60,000 patients reported lower mortality in HFpEF ( $\mathrm{EF} \geq 50 \%$ ) compared to HFrEF. However, the evaluation itself does not make a distinction between outpatients or patients with DHF, which may influence the outcomes. ${ }^{29}$ Only a handful of published studies have focused on patients with HFmrEF which, comparable to the sample of this study, have shown an intermediate group with mortality rates similar to those in the other HF groups. ${ }^{30}$ Consequently, the population data shown is this report are consistent with recently published studies that used data from hospitalized patients. ${ }^{30}$ When the outcomes were analyzed, after the one-year follow-up evaluation, including death by any cause and admission due to HF, there were similarities between HFmrEF and HFpEF, with HFrEF patients presenting the worst prognosis. ${ }^{31}$ It was not possible to establish comparisons with national data due to the scarcity of publications.

In general, heart failure mortality prediction scores have limited accuracy..$^{10}$ The BIOSTAT-CHF ${ }^{32}$ emerged as a comprehensive European program designed to develop and validate risk prediction models, in an attempt to minimize this problem. The authors highlighted the small percentage of models validated in a separate cohort and the fact these models performed only moderately (c-statistic values 0.71 and 0.63 for mortality and HF hospitalization, respectively). Using a multivariable model (249), they found that the strongest predictors of mortality were urea and serum sodium. It is interesting to highlight that there was no significant difference between patients with acute or chronic HF. An LVEF cut-off of $45 \%$ was used to distinguish HFrEF from HFpEF, and no similarities were found between the risk factors of the population studied and the validation cohort, which has also included a small percentage of patients with an LVEF greater than $45 \%$. The LVEF cut-off adopted may be a limiting factor for extrapolation of any findings to the HFmrEF group. ${ }^{32}$

A recent Swedish HF registry has reported that chronic kidney disease is a strong predictor of mortality in both HFmrEF and HFrEF patients. ${ }^{33}$ However, in the population assessed here, renal involvement, whether due to previous kidney disease or to increased urea at admission, was the only mortality predictor that revealed similarities between the $3 \mathrm{HF}$ 
groups. Similarly, urea has been strongly associated to in-hospital death risk in traditional scores, such as BIOSTAT $^{32}$ and ADHERE. ${ }^{10}$ The persistence of urea in all these models indicates its prognostic strength. Thus it should be the object of more attention by those who monitor patients with HF, due to the higher death risk among HFmrEF individuals (6 times more), for instance. It is possible to suggest that the presence of valve disease as a factor of worse prognosis in HF patients with LVEF greater than $40 \%$ indicates that it could be the etiology of heart failure. At the same time, it involves clinical characteristics and challenges, especially among the elderly population, due to the small number of randomized clinical trials. Consequently, treatment is also less well established.

It is necessary to highlight the efficacy of medication, since recent international publications, as observed by this study, originally in Brazil, have demonstrated significant benefits of beta-blockers both in $\mathrm{HFrEF}^{32}$ and $\mathrm{HFmrEF},{ }^{34}$ thus suggesting benefits in all HF patients with an ejection fraction less than or equal to $49 \%$. This fact has not been registered in randomized clinical trials which have included exclusively patients with systolic HF. ${ }^{17,35}$ A recent meta-analysis involving 11 randomized studies and over 14,000 patients on the use of beta-blockers has confirmed their benefits in patients with $\mathrm{EF}<50 \%$ and sinus rhythm. ${ }^{36}$ As for ACEI/ARB, it is important to point out that the results only remained among HFmrEF patients, with a 5 times increased mortality among those who did not receive the medication. In the OPTIMIZEHF registry, although the use of ACEI/ARB has been associated with less mortality and hospital readmission within 30- and 90-days in HFrEF patients, such benefit has not been observed among the HFmrEF and HFpEF groups..$^{28}$ In a subanalysis of CHARM, the benefit of candesartan was also seen in patients with HFmrEF. ${ }^{37}$ Furthermore, in spite of the results of the TOPCAT trial, studies have found benefits of spironolactone in patients with EF between $45-49 \%{ }^{38}$ which was not observed in this study's population. Therefore, HFmrEF signals a transition behavior or a "gray area" in which a better characterization of this group may soon bring prognostic and therapeutic benefits.

\section{Limitations}

The study is based on patients with a clinical picture of decompensated heart failure, and their physical and laboratory variables were collected at admission on a database. Thus information was collected retrospectively. Other potentially relevant variables, such as natriuretic peptide levels, were not selected in the multivariate model because data was not available in all patients.

\section{Conclusion}

The demographic/clinical profiles of HFmrEF are intermediate, between those of HFpEF and HFrEF. Kidney disease was the only risk factor for death in HFrEF and HFpEF, whereas valve disease and increased urea levels were associated with HFmrEF. The use of ACEI/ARB and beta-blockers, already established as mortality reducing drugs in HFrEF, has been independently related to better evolution in this HF group. The benefits of the beta-blockers in HFmrEF have also been reported, which indicates this conduct in the intermediate scenario, since there have been no recommendations based on guidelines.

\section{Author contributions}

Conception and design of the research: Cavalcanti GP, Sarteschi C, Gomes GES, Medeiros CA, Pimentel JHM, Lafayette AR, Almeida MC, Oliveira PSR, Martins SM. Acquisition of data: Cavalcanti GP, Sarteschi C, Gomes GES, Medeiros CA, Pimentel JHM, Lafayette AR, Almeida MC, Oliveira PSR, Martins SM. Analysis and interpretation of the data: Cavalcanti GP, Sarteschi C, Gomes GES, Medeiros CA, Pimentel JHM, Lafayette AR, Almeida MC, Oliveira PSR, Martins SM. Statistical analysis: Cavalcanti GP, Sarteschi C, Gomes GES, Medeiros CA, Pimentel JHM, Lafayette AR, Almeida MC, Oliveira PSR, Martins SM. Writing of the manuscript: Cavalcanti GP, Sarteschi C, Gomes GES, Medeiros CA, Pimentel JHM, Lafayette AR, Almeida MC, Oliveira PSR, Martins SM. Critical revision of the manuscript for intellectual content: Cavalcanti GP, Sarteschi C, Gomes GES, Medeiros CA, Pimentel JHM, Lafayette AR, Almeida MC, Oliveira PSR, Martins SM.

\section{Potential Conflict of Interest}

No potential conflict of interest relevant to this article was reported.

\section{Sources of Funding}

There were no external funding sources for this study. 


\section{Study Association}

This article is part of the Thesis of monograph of the work of conclusion of the residency in cardiology submitted by Gabriela Paiva Cavalcanti, from Real Hospital Português de Beneficência de Recife.

\section{Ethics approval and consent to participate}

This study was approved by the Ethics Committee of the Centro de Pesquisa da Universidade
Católica de Pernambuco under the protocol number 70897517.8.0000.5206. All the procedures in this study were in accordance with the 1975 Helsinki Declaration, updated in 2013. Informed consent was obtained from all participants included in the study.

\section{References}

1. Kapoor JR, Kapoor R, Ju C, Heidenreich PA, Eapen ZJ, Hernandez $\mathrm{AF}$, et al. Precipitating clinical factors, heart failure characterization, and outcomes in patients hospitalized with heart failure with reduced, borderline, and preserved ejection fraction. JACC Heart Fail. 2016;4(6):464-72.

2. Banerjee P. Heart failure with preserved ejection fraction: a clinical crisis. Int J Cardiol. 2016 Feb 1;204:198-9.

3. Rickenbacher P, Kaufmann BA, Maeder MT, Bernheim A, Goetschalckx $\mathrm{K}$, Pfister $\mathrm{O}$, et al. Heart failure with mid-range ejection fraction: a distinct clinical entity? Insights from the trial of intensified versus standard medical therapy in elderly patients with congestive Heart Failure ( TIME-CHF ). Eur J Heart Fail. 2017;19(12):1586-96.

4. Pascual-Figal DA, Ferrero-Gregori A, Gomez-Otero I, Vazquez R, Delgado-Jimenez J, Alvarez-Garcia J, et al. Mid-range left ventricular ejection fraction: clinical profile and cause of death in ambulatory patients with chronic heart failure. Int J Cardiol. 2017 Aug 1;240:265-70.

5. Yancy CW, Jessup M, Bozkurt B, Butler J, Casey DE Jr, Drazner MH, et al. $2013 \mathrm{ACCF} / \mathrm{AHA}$ guideline for the management of heart failure: a report of the American College of Cardiology Foundation/American Heart Association Task Force on Practice Guidelines. J Am Coll Cardiol. 2013;62(16):e147-239.

6. Ponikowski P, Voors AA, Anker SD, Bueno H, Cleland JGF, Coats AJS, et al. 2016 ESC guidelines for the diagnosis and treatment of acute and chronic heart failure: The Task Force for the diagnosis and treatment of acute and chronic heart failure of the European Society of Cardiology (ESC)Developed with the special contribution of the Heart Failure Association (HFA) of the ESC. Eur Heart J. 2016;37(27):2129-2200.

7. Hunt SA. American College of Cardiology; American Heart Association Task Force on Practice Guidelines (Writing Committee to Update the 2001 Guidelines for the Evaluation and Management of Heart Failure) ACC/AHA 2005 Guideline update for the diagnosis and management of chronic heart failure in the adult: a report of the american college of cardiology/american heart association task force on practice guidelines (writing committee to update the 2001 guidelines for the evaluation and management of heart failure). J Am Coll Cardiol. 2005;46(6):e1-82.

8. Colafranceschi AS, Freitas Jr AF, Ferraz AS, Biolo A, Barretto ACP, Ribeiro ALP, et al. Diretriz Brasileira de Insuficiência Cardíaca Crônica e Aguda. Arq Bras Cardiol. 2018;111(3):436-539.

9. Lang RM, Badano LP, Mor-Avi V, Afilalo J, Armstrong A, Ernande $\mathrm{L}$, et al. Recommendations for cardiac chamber quantification by echocardiography in adults: An update from the american society of echocardiography and the European Association Of Cardiovascular Imaging. Eur Heart J Cardiovasc Imaging. 2015;16(3):233-70.

10. Fonarow GC, Heywood JT, Heidenreich PA, Lopatin M, Yancy CW, ADHERE Scientific Advisory Committee and Investigators. Temporal trends in clinical characteristics, treatments, and outcomes for heart failure hospitalizations, 2002 to 2004: findings from Acute

Decompensated Heart Failure National Registry (ADHERE). Am Heart J. 2007;153(6):1021-8.

11. Organização Mundial da Saúde. Série de relatórios técnicos no182. Geneva: WHO; 1959.

12. Ho KK, Pinsky JL, Kannel WB, Levy D. The epidemiology of heart failure: the Framingham study. J Am Coll Cardiol. 1993;22(4 Suppl A):6A-13A.

13. Katsi V, Georgiopoulos G, Laina A, Koutli E, Parissis J, Tsioufis C, et al. Left ventricular ejection fraction as therapeutic target: is it the ideal marker? Heart Fail Rev. 2017;22(6):641-55.

14. Kinno M, Nagpal P, Horgan S, Waller AH. Comparison of echocardiography, cardiac magnetic resonance, and computed tomographic imaging for the evaluation of left ventricular myocardial function: part 1 (Global Assessment). Curr Cardiol Rep. 2017;19(1):9.

15. SOLVD Investigators, Yusuf S, Pitt B, Davis CE, Hood WB Jr, Cohn JN. Effect of enalapril on mortality and the development of heart failure in asymptomatic patients with reduced left ventricular ejection fractions. N Engl J Med. 1992;327(10):685-91.

16. Pitt B, Zannad F, Remme WJ, Cody R, Castaigne A, Perez A, et al. The effect of spironolactone on morbidity and mortality in patients with severe heart failure. N Engl J Med. 1999;341(10):709-17.

17. Dargie HJ, Lechat P. The cardiac insufficiency bisoprolol study II (CIBISII): a randomised trial. Lancet. 1999;353(9146):9-13.

18. Albuquerque DC, Souza Neto JD, Bacal F, Rohde LEP, BernardezPereira S, Berwanger O, et al. I Brazilian registry of heart failure - clinical aspects, care quality and hospitalization outcomes. Arq Bras Cardiol. 2015;104(6):433-42.

19. Rohde LE, Clausell N, Ribeiro JP, Goldraich L, Netto R, Dec GW, et al. Health outcomes in decompensated congestive heart failure: a comparison of tertiary hospitals in Brazil and United States. Int J Cardiol. 2005;102(1):71-7.

20. Abraham WT, Fonarow GC, Albert NM, Stough WG, Gheorghiade M, Greenberg BH, et al. Predictors of in-hospital mortality in patients hospitalized for heart failure: insights from the Organized Program To Initiate Lifesaving Treatment In Hospitalized Patients With Heart Failure (OPTIMIZE-HF). J Am Coll Cardiol. 2008;52(5):347-56.

21. Pocock SJ, Wang D, Pfeffer MA, Yusuf S, McMurray JJ, Swedberg KB, et al. Predictors of mortality and morbidity in patients with chronic heart failure. Eur Heart J. 2006;27(1):65-75.

22. Lam CSP, Solomon SD. The middle child in heart failure: heart failure with mid-range ejection fraction ( $40-50 \%)$. Eur J Heart Fail. 2014;16(10):1049-55.

23. Andronic AA, Mihaila S, Cinteza M. Heart failure with mid-Range ejection fraction - a new category of heart failure or still a gray zone. Maedica (Buchar). 2016;11(4):320-4. 
24. Fonarow GC, Abraham WT, Albert NM, Stough WG, Gheorghiade M, Greenberg BH, et al. Factors identified as precipitating hospital admissions for heart failure and clinical outcomes. Arch Intern Med. 2008;168(8):847-54

25. Borlaug BA, Redfield MM. Diastolic and systolic heart failure are distinct phenotypes within the heart failure spectrum. Circulation. 2011;123(18):2006-13

26. Kalogeropoulos AP, Fonarow GC, Georgiopoulou V, Burkman G, Siwamogsatham S, Patel A, et al. Characteristics and outcomes of adult outpatients with heart failure and improved or recovered ejection fraction. JAMA Cardiol. 2016;1(5):510-8.

27. Kelly JP, Mentz RJ, Mebazaa A, Voors AA, Butler J, Roessig L, et al. Patient selection in heart failure with preserved ejection fraction clinical trials. J Am Coll Cardiol. 2015;65(16):1668-82.

28. Fonarow GC, Stough WG, Abraham WT, Albert NM, Gheorghiade M, Greenberg BH, et al. Characteristics, treatments, and outcomes of patients with preserved systolic function hospitalized for heart failure: a report from the OPTIMIZE-HF registry. J Am Coll Cardiol. 2007;50(8):768-77.

29. Martínez-Sellés M, Doughty RN, Poppe K, Whalley GA, Earle N, Tribouilloy C, et al. Gender and survival in patients with heart failure: interactions with diabetes and aetiology. Results from the MAGGIC individual patient meta-analysis. Eur J Heart Fail. 2012;14(5):473-9.

30. Gómez-Otero I, Ferrero-Gregori A, Varela Román A, Seijas Amigo J Pascual-Figal DA, Delgado Jiménez J, et al. Mid-range ejection fraction does not permit risk stratification among patients hospitalized for heart failure. Rev Esp Cardiol (Engl Ed). 2017;70(5):338-46.

31. Chioncel O, Lainscak M, Seferovic PM, Anker SD, Crespo-Leiro MG, Harjola VP, et al. Epidemiology and one-year outcomes in patients with chronic heart failure and preserved, mid-range and reduced ejection fraction: an analysis of the ESC Heart Failure Long-Term Registry. Eur J Heart Fail. 2017;19(12):1574-85.
32. Voors AA, Ouwerkerk W, Zannad F, van Veldhuisen DJ, Samani NJ, Ponikowski $\mathrm{P}$, et al. Development and validation of multivariable models to predict mortality and hospitalization in patients with heart failure. Eur J Heart Fail. 2017;19(5):627-34

33. Löfman I, Szummer K, Dahlström U, Jernberg T, Lund LH. Associations with and prognostic impact of chronic kidney disease in heart failure with preserved, mid-range, and reduced ejection fraction. Eur J Heart Fail. 2017;19(12):1606-14.

34. Tsuji K, Sakata Y, Nochioka K, Miura M, Yamauchi T, Onose T, et al. Characterization of heart failure patients with mid-range left ventricular ejection fraction-a report from the CHART-2 Study. Eur J Heart Fail. 2017;19(10):1258-69.

35. MERIT-HF Study Group. Effect of metoprolol CR/XL in chronic heart failure: metoprolol CR/XL randomised intervention trial in congestive heart failure (MERIT-HF). Lancet. 1999;353(9169):2001-7.

36. Cleland JGF, Bunting K V, Flather MD, Altman DG, Holmes J, Coats AJS, et al. Beta-blockers for heart failure with reduced, mid-range, and preserved ejection fraction: an individual patient-level analysis of doubleblind randomized trials. Eur Heart J. 2018;39(1):26-35.

37. Lund L. European Society of Cardiology. Candesartan provides similar benefit for patients with mid- range ejection fraction as those with reduced ejection fraction [Internet]. 2017 [citado fev. 2019]. Disponível em: https://www.escardio.org/Congresses-\&-Events/Heart-Failure/ Congress-resources/News/candesartan-provides-similar-benefit-forpatients-with-mid-range-ejection-fracti.

38. Solomon SD, Claggett B, Lewis EF, Desai A, Anand I, Sweitzer NK, et al. Influence of ejection fraction on outcomes and efficacy of spironolactone in patients with heart failure with preserved ejection fraction. Eur Heart J. 2016;37(5):455-62. 